Мёдова A.A.

\title{
Музыкальная модальность как тип мышления: логика модального лада
}

Аннотация: Статья посвящена выделению характерных черт музыкальной модальности в гармоническом аспекте ее реализации. Цель статьи - продемонстрировать особенности модальной гармонии как особого типа музыкального мышления. Предметом исследования является специфика построения и организации модальных ладов народной и средневековой музыки. На примере католических церковных модусов, русской народной песни и индийских ладов тхат автор рассматривает логику звуковысотности и функциональных отношений внутри модального лада. Анализируются принципы оформления ступенного состава ладов в звуковом континууме, гармонические роли их тонов, а также онтологические аспекты модального лада. Исследование базируется на методе гармонического анализа с опорой на сравнительный анализ принципов модальной и тональной ладовых организаций. С целью интерпретации модальных ладовых отношений как типа мышления и эстетического мировоззрения автор прибегает к философской идее тождества формы и содержания, постулируемой в модальных онтологиях. Новизна позиции автора заключается в логико-онтологическом подходе к интерпретации гармонических явлений, а также в обобщении специфики европейских, русских и индийских ладов как исторических форм модального мышления в музыке. В ходе исследования выделяются такие качества гармонической модальности как невозможность унификации ладов, реализация лада в виде любого количества ступеней, потенциально имеющих различные звуковысотные варианты, свертывание каждой ступенъю всех ладовых функций, и наоборот, реализация одной и той же функции, в том числе и главной опоры, несколькими ступенями. Эти качества говорят об особой пластичности модального музыкального мышления, в рамках которого такие явления как лад, мелодия (напев) и жанр тяготеют к неразличимости.

Ключевъе слова: Модус, модальность, гармония модальная, лад модальный, тональность, мышления модальное, рага, тхат, ладовая переменность, целостность модальная.

Review: The paper is devoted to the typical features of music modality from the point of view of their harmonic imlementation. The purpose of the article is to demonstrate the features of modal harmony as a special type of musical thinking. The subject of the research is the peculiarities of the composition of folk and medieval modal moods. Based on the examples of the Catholic Church moduses, Russian folk songs and Indian traditional moods "tkhat" the author considers the logic of sound sequences and functional relationships within the modal moods. The author also analyzes the principles of the composition of the sequences of moods in the sound continuum, harmonic roles of their tones and ontological aspects of the modal mood. The research is based on the method of harmonic analysis and comparative analysis of the principles of modality and tonality of moods. For the purpose of interpreting modal moods as a type of thinking and aesthetic world view, the author has also appealed to the philosophical idea of the unity of substance and form postulated in modal ontologies. The novelty of the author's research is caused by the fact that the author applies the logicalontological approach to the interpretation of harmonic phenomena and summarizes peculiarities of European, Russian and Indian moods as historical forms of modal thinking in music. In the course of the research the author has defined such features of harmonic modality as the impossibility of the unification of moods, reproduction of moods in a form of any number of sequences that potentially have different pitches of sound, folding of each sequence of modal functions and, on the contrary, performance of one and the same function at different levels. These qualities speak of particular plasticity of modal musical thinking within which such phenonena as the mood, melody (tune) and musical form tend to be indistinguishable.

Keywords: Modality, modal harmony, modal mood, tonality, modal thinking, raga, tkhat, modal variability, modus, modal integrity.

Исследование выполнено при поддержке РГНФ в рамках проекта № 15-53-оооо2 «Теория модальности: междисциплинарное методологическое исследование». 
$\Pi$ онятиями модальность и модус в музыкальной теории обозначаются стилистические особенности музыки, обобщенно называемой старинной, то есть музыки, созданной в промежутке от периода архаики и до конца эпохи Возрождения. Модальностью называется так же особый тип музыкального мышления или особая логика музыкального языка, проявляющая себя на уровне гармонических структур, ладов и на уровне ритма. На уровне музыкального содержания музыкальные модусы - это архаические этосы или раса, т.е. типизированные состояния духа, вызываемые тем или иным ладом, мелодической моделью, ритмической формулой. Однако, это не означает, что современная музыка лишена содержательного модуса. На более «высоком» уровне музыкальная модальность смыкается с модальностью текста и представляет собой спектр наклонений сознания к миру, оформляющийся в измерении эстетического смысла.

Смысловые аспекты музыкального модуса иллюстрирует трактат композитора и теоретика высокого итальянского Возрождения Джозеффо Царлино Le Istitutioni harmoniche (1558), созданный на рубеже перехода от модальной гармонии к вытеснившей ее в XVII веке гармонии тональной. Для Царлино модус (modo) - это, прежде всего, форма лада; он упоминает семь бытующих звукорядов, называя их модусами.

Царлино выделяет смысловые аспекты термина modo, фиксирующие значения меры, порядка, самоограничения, организации. «Утверждая дефиницию модуса мы скажем, вместе с Боэцием, что модус есть определенная конституция всех нот звукоряда, что это устройство подобно корпусу мелодии, которая возникает из сочетания консонансов» [1]. Суть модуса объясняется так же с помощью его «толковательных» терминов - форма, качество, разновидность: «Мы должны сказать, что модус - это определенная форма или качество гармонии, обнаруживаемой в каждой разновидности диапасона» [2].

Музыкальная модальность реализуется во взаимообратимых измерениях формы и содержания. В плане содержания она является аналогом тождества духа и тела: это космогоническая, мировоззренческая или этическая суть музыкальных ладов и их элементов, а так же музыкального тематизма и драматургии в целом. Выдающиеся теории понимаемой таким образом модальности разработаны от- ечественными музыковедами Е.Н. Назайкинским и В.В. Медушевским [3].

В плане формы модальностью является определенный тип гармонических и ритмических структур. Во данном значении этот термин обозначает особый тип гармонического мышления, характерный для архаических и древних культур, Средневековья, Возрождения, современной академической музыки и джаза.

Явление музыкального модуса многогранно. Оно представляет научный интерес по целому ряду причин. Одна из них - это непостижимое для рационального сознания тождество древних модусов-ладов космическим процессам, периодам времени и состояниям человеческого духа, фундированное особым типом мышления. На уровне собственно музыкального языка перспективны исследования общности принципов ритмической, гармонической и интонационной модальности. С точки зрения междисциплинарных исследований актуален вопрос, возможно ли понимать музыкальные модусы как нечто подобное модусам грамматическим и логическим, но реализуемое в звуковысотном пространстве и в ритме, или же между модусами этих языков нет никакой связи?

В этой статье мы обратимся к особенностям модальных ладов фольклора и средневековой музыки с целью выделения характерных принципов модального гармонического мышления. Речь пойдет исключительно о логике построения и развертывания модальных ладов.

\section{Онтология модуса-лада}

Под ладом в музыкальной теории понимается звукоряд из любого количества ступеней. Представление о ладах сложилось в античности и было систематизировано в Европе приблизительно в IX веке, тогда и появилась система так называемых церковных модусов. Лад мыслится как ряд музыкальных звуков, расположенный от самого низкого к самому высокому или наоборот (расположение ладов «сверху вниз» характерно для индийской музыкальной теории, тем не менее, мы приводим ниже индийские лады тхат в привычном для нас варианте от нижнего звука к верхнему). Идея лада была получена путем абстрагирования высоты звуков от напева - по сути лад является расположением всех звуков данного напева «по порядку» на шкале музыкальных высот. 
Человечество никогда не осваивало звуковое пространство как единую систему. Область музыкальных высот всегда дифференцировалась на определенные сегменты, имеющие точно установленный объем. Таковыми сегментами в доклассический период античной культуры были тетрахорды, т.е. звукоряды, состоящие из четырех ступеней. В Средневековье в качестве осмысленного сегмента звукового пространства выступали шести- или семиступенные лады-модусы.

Выделение конкретного набора музыкальных тонов в качестве освоенного звуковысотного пространства уже является актом музыкального мышления, поскольку здесь проявляются представления о музыкальном строе. Последний может включать от ста до трех разных звуков, быть диатоническим, хроматическим, четвертитоновым, с нормированным или ненормированным расстоянием между соседними высотами. Музыкальный строй есть нечто сродни фонетическому составу языка: в разных языках в качестве смыслоразличительного избирается различный набор фонем, с чем связаны проблемы произношения при изучении иностранных языков. Трудности осваивающего неродной язык человека заключены в большей степени не в том, что он не может извлечь требуемый звук-фонему, а в том, что он не может его «услышать», поскольку в его родном языке она не выделена как самостоятельный элемент из всего множества возможных звуковых единиц. В перспективе исследований логики музыкального языка правомерно понимать тоны музыкального строя различных культур как явление, однопорядковое фонетическому составу различных языков.

Исследование модальных ладов выявляет еще одно пересечение музыкальной гармонии и грамматики. И лад, и грамматические структуры не являются свойствами, привнесенными в музыкальный и вербальный языки. Это не дополнительные факторы, как если бы лад был характеристикой мелодии, которую мелодия может иметь или не иметь, наподобие тембра музыкального инструмента ее исполняющего, который может быть, в принципе любым. Тембр является акциденцией мелодии, то есть не обязательной ее характеристикой. Как самодостаточная художественная целостность, мелодия может быть исполнена на любом подходящем по тесситуре инструменте или же спета, но может так же и не исполняться вовсе, оста- ваясь только записанной - от этого существо мелодии не изменится.

Отношение мелодии к ее ладу имеет иную логику, которая делает явными отличия модального и тонального типов музыкального мышления. В тональности, сформировавшейся к концу XVI века, реализуются лишь две универсальные ладовые формы, мажор и минор, и они унифицированы - это всегда одни и те же два звукоряда, которые разворачиваются от любого звука темперированного музыкального строя. Структура этих звукорядов отражена в нотном примере № 1.

Нотный пример № 1. Звукоряды мажора и минора.
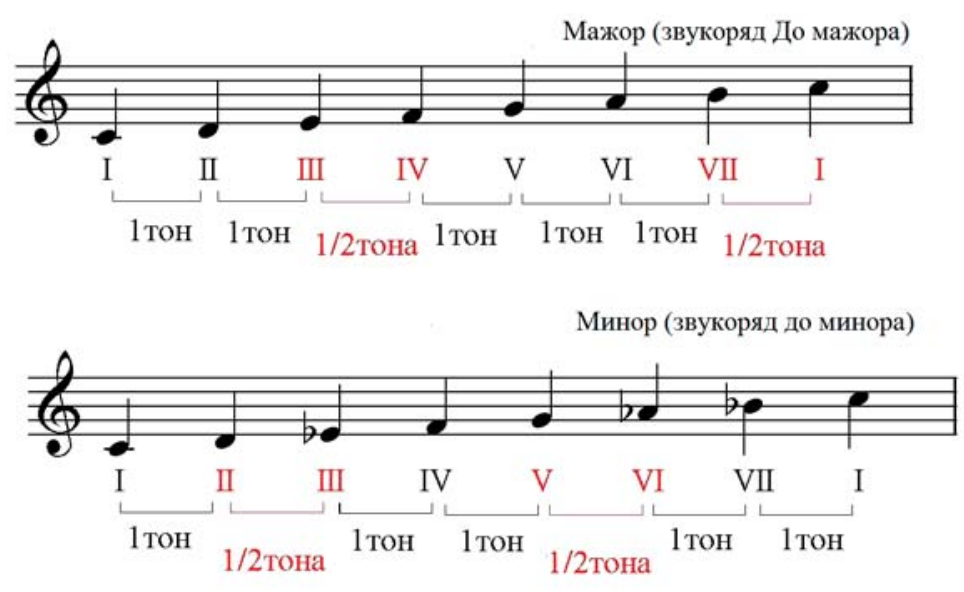

В мажоре третья и четвертая, а так же седьмая и первая ступени всегда будут отстоять друг от друга на полтона, т.е. на минимальное в рамках европейского музыкального строя расстояние между звуками. Все остальные ступени мажора находятся на расстоянии тона. В миноре полутоны разделяют II и III, V и VI ступени, остальные ступени отстоят друг от друга на тон. Это соотношение воспроизводится от любого из 12-и разных по высоте звуков музыкальной шкалы (звуки на расстоянии октавы, то есть с разницей частоты колебаний в 2, 4, 8 и так далее раз разными по высоте не считаются). Таким образом, в распоряжении тонального мышления имеется 12 мажорных и 12 минорных тональностей.

Унификация ладов объясняет, почему при смене тональности меняется лишь высота звучания мелодии или всего музыкального произведения, сами же они остаются неизменны и узнаваемы. Так, ради удобства исполнения романсы и арии часто бытуют в 
нескольких тональностях, выбор конкретной тональности зависит от диапазона певца. К примеру, ария Германа «Что наша жизнь? - Игра» из седьмой картины оперы П.И. Чайковского «Пиковая дама» известна в трех тональностях - си мажоре, сибемоль мажоре и ля мажоре. Изначально композитор написал ее в си мажоре, но по просьбе солиста императорских театров Николая Фигнера, исполнявшего партию Германа, перенес ее на полтона ниже, в си-бемоль мажор, в этом варианте она исполняется наиболее часто.

В тональном мышлении каждая конкретная тональность, в которой реализуется произведение, есть так же своего рода акциденция (если не меняется ладовое наклонение, то есть, мажор не заменяется минором и наоборот).

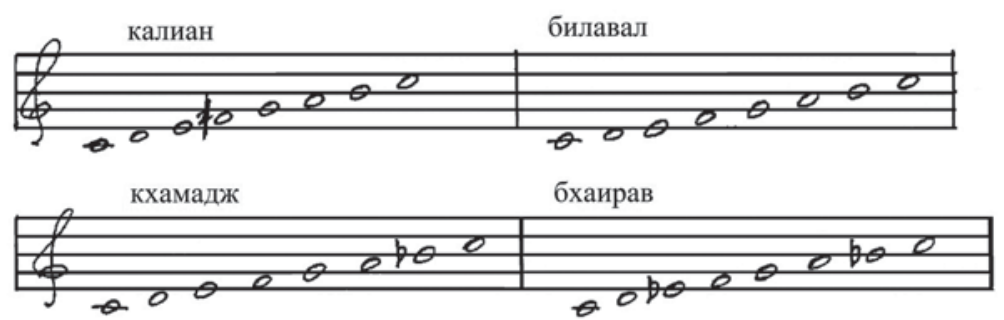

Нотнъй пример № 2. Индийские ладъ тхат [4]

Неотъемлема от сути музыкального произведения лишь сама тональная структура, высота же ее реализации может варьироваться. Но модальное мышление имеет иные принципы. Модальные лады уникальны по своему звуковысотному составу и функциональности тонов, поэтому мелодия здесь, по сути, тождественна ладу. Она не транспонируется, не переносится в другой модальный лад, поскольку в таком случае это будет уже совершенно иная мелодия с другими интервальными ходами, изменившаяся до неузнаваемости. Ситуация с модусами-ладами аналогична пониманию бытия в философии: невозможно мыслить бытие как нечто, что добавляется к сущности вещей, поскольку бытие и есть сами вещи, тем или иным образом существующие. Модус-лад так же есть само музыкальное произведение как таковое, так как невозможно изменить лад не изменив этим весь интонационный строй музыки и, следовательно, ее смысл. Аналогичным образом модальность в языке смыкается с собственно грамматикой.

\section{Звуковысотный состав модуса-лада}

Уникальность функциональной логики и ступенных составов модальных ладов предполагаетих неисчерпаемое многообразие. Их количество потенциально стремится к бесконечности, так же, как и число возможных различных предложений в словесном языке.

Тем не менее, попытки унифицировать все многообразие модусов-ладов не раз предпринимались в истории музыки. По преданию Бог Кришна был полностью опьянен собственной игрой на флейте и, когда он начинал петь, шестнадцать тысяч его спутниц следовали за ним, при этом каждая пела свою рагу. Таким образом, существовало шестнадцать тысяч мифологических модусов-раг. В 15 веке поэт и музыкант Локхан выделил 12 основных ладов-тхатов, которым соответствовали раги. Учитывая, что каждая рага-лад имеет женский вариант - рагиню, а та имеет шестнадцать дочерних вариантов - по восемь «сыновей» и «невесток», число раг в музыкальной практике превышало две сотни. Уже в начале XX века индийский теоретик Вишну Нарайян Бхаткханде (1860-1936) заново систематизировал раги и ввел систему их классификации по 10 группам тхат (см. нотный пример № 2).

По сравнению с тональной системой, в образовании звукорядов этих ладов нет никакой видимой логики. Единственный стабильный элемент - это сохранение неизменного «каркаса» в виде тонической квинты; первая и пятая ступень (тоны до и соль) не имеют высотных вариантов, не альтерируются. Остальные ступени в разных ладах могут представать в двух вариантах. В записи, к примеру, шестой ступени это выражается так - в пяти ладах она представлена как звук ля, в других пяти как ее пониженный вариант ля-бемоль. В целом 
складывается представление об изначальном диатоническом семиступенном ряде, высота всех тонов которого, кроме двух «отправных», предполагает возможность реализации в двух звуковысотных вариантах.

Но все отнюдь не так просто. Индийские лады тхат демонстрируют еще одно не поддающееся унификации и систематизации качество - они имеют разный ступенной состав в зависимости от того, движется ли мелодия вверх или же вниз.

\section{Нотный пример № 3 . Лад мулътани в восходящем и нисходящем движении [5]}

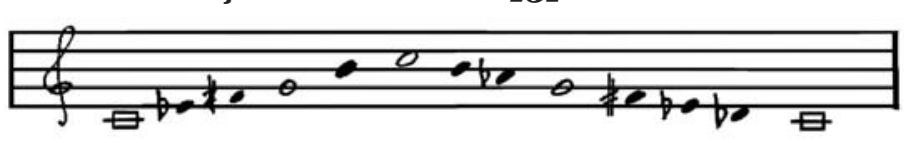

Музыкальный лад определяется как звуковысотная система соподчинения определенного ряда звукоэлементов (тонов, аккордов, соноров), логически дифференцированных по степени и форме их тормозящей или движущей роли [8]. Гармонические структуры имеют один или несколько центров тяготения, что называется эффектом централизации. Центральный, устойчивый звук лада имеет выраженную энергию торможения, он организует завершение мелодических оборотов, фраз построений. Неустойчивый тон, напротив, «стремится» перейти в устой, он имеет энергию движения, развертывания.

Таким образом, гармоническое мышление функционально; речь идет здесь о специфических функциях, создающих условия «продвижения» музыкального материала во времени. Ладовое мышление - это принципы наделения тех или иных ступеней звукоряда опорностью или неопорностью, устойчивостью и неустойчивостью, или, иначе, распределений «ролей», которые тоны «играют» в напеве.

Под гармоническими функциями применительно к модальным структурам подразумевается прежде всего опорность или неопорность тонов лада, т.е. их устойчивость или неустойчивость. В модальном ладу есть тоны ключевые, выполняющие роль инициального и/или заключительного звука, и второстепенные, проходящие, вспомогательные, а так же тоны вводные, максимально тяготеющие к устойчивым. В противоположном модальному типе гармонического мышления, т.е. в тональности, так же имеют место и звукоряды, и подобные функции их ступеней. Но логика связи данной функции с данной музыкальной высотой принципиально иная.

Все ладовые функции в тональности регламентированы и строго закреплены за ступенями и строящимися на них аккордами; их задает сама гармоническая структура. Центр тональных тяготений всегда один, и располагается он на первой ступени лада это тоника; акустическое господство тоники безраздельно и может быть нарушено лишь переходом в другую тональность. Наиболее активная, неустойчивая тональная функция - это доминанта, располагающаяся на пятой ступени лада. Еще один вид тональных ладовых функций - субдоминанта, группирующая IV и II ступени, которая может напрямую соспоставляться с тоникой или предшествовать доминанте, и, наконец, существуют функцио- 
нально нейтральные медианты, VI и III ступени. Тональность - это жестко заданная, воспроизводимая от разных высот, «априорная» система гармонических функций и тяготений.

Каждый модальный лад, напротив, организован уникально. К примеру, в средневековых модусах григорианского хорала различают ступени модально сильные, представляющие собой конструктивную опору, на которых обычно строилась речитация и заканчивались фразы, и слабые ступени, примыкающие к сильным. Слабые ступени лада выполняли роль вспомогательных и проходящих звуков между сильными [9].

\section{Нотнъй пример № 4. Средневековъе западноевропейские модусъ [10]}

плагальных ладов (т.е. ладов, производных от автентических путем такого изложения звукоряда, при котором финалис не является самым нижним звуком) так же меняют положение - они отстоят друг от друга то на терцию (через один звук), то на кварту (через два звука). Это указывает на отсутствие универсальной функциональной структуры лада.

Классическими образцами высокоразвитого модального мышления являются так же индийские раги, представляющие собой одновременно жанр, лад, мелодическую модель и типизированное содержание. Каждая индийская рага-лад имеет главный звук, вади, второй по значению звук - самавади, группу подчиненных звуков - анувади и диссонирующий звук - вивади. В индийской музыкальной культуре лады (grâma) отличаются

\section{(Знаком $\bigcirc$ отмечены финалисы, знаком $\triangle$ реперкуссы)}

Автентические лады средневековой теории

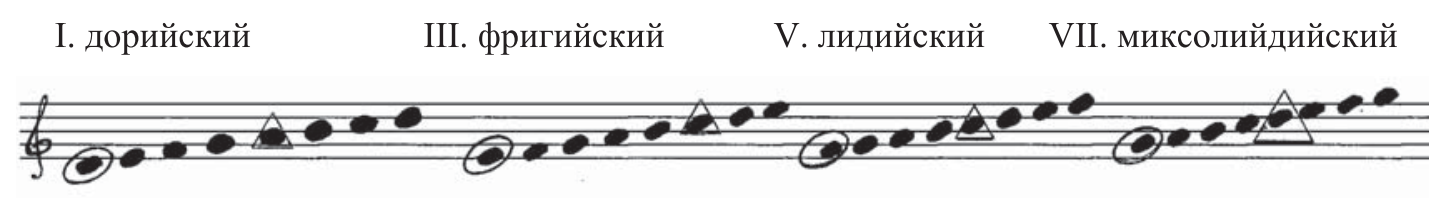

\section{Плагальные лады средневековой теории}

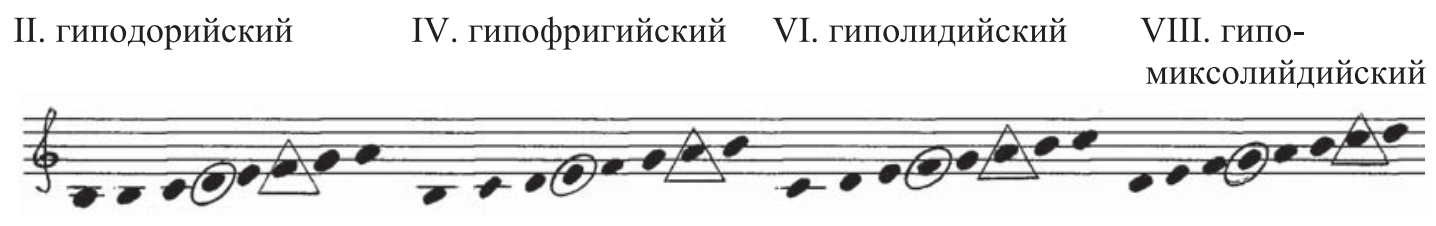

Для средневековых григорианских ладов и ладов эпохи Возрождения, в которых создавалась многоголосная полифоническая музыка, значимы такие ладовые функции, как финалис (тон или созвучие, заканчивающее пьесу, воспринимаемое как итоговая опора) и реперкусса (второй после финалиса устой модально-гармонического лада, наиболее употребимое в данном ладу созвучие или тон, основной тон речитации). Как видно из нотного примера № 4, ладовые функции не закреплены жестко за одними и теми же ступенями лада, как это имеет место в тональности, т.е. финалисы и реперкуссы не имеют четкого соответствия тем или иным ступеням звукоряда. Так, реперкусса фригийского лада расположена на VI от финалиса ступени, тогда как у всех остальных автентических ладов она совпадает с V ступенью. Финалисы и реперкуссы не звуковым составом, а положением тоники. Основной и опорной может становиться любая ступень двух употребительных звуковысотных шкал: тоникой поочередно становится любая из семи ступеней sa-grâma или ma-grâma, так реализуется четырнадцать ладов [11].

Тоны модальных ладов могут быть нейтральными в плане устойчивости, конкурировать между собой в опорности или быть опорами «второго плана». Причем эти функции не связаны однозначно с положением ступеней в ладу, т.е. с интервальным расстоянием между данной ступенью и главным устоем (если таковой имеется). Более того, само количество ступеней в модальных ладах не регламентировано, в отличие от семиступенных мажора и минора.

В отличие от классической тональности, модальные лады не имеют одного, четко 
определенного центрального тона, который был бы исходным и финальным пунктом гармонического развития - таких тонов может быть несколько на протяжении всего произведения («рассредоточенная тоника») или же тоники могут быть разными в разных разделах музыкального произведения («блуждающая тоника»).

Характерная особенность модального гармонического мышления, невозможная в тональном мышлении, заключена в том, что одна и та же ступень модального лада может совмещать разные функции, например, быть проходящим звуком и временной опорой. С точки зрения тонального мышления это так же парадоксально, как одновременное нахождение одного и того же предмета в двух разных местах с точки зрения классической рациональности и здравого смысла. Но модальная логика гармонических отношений тонов обусловлена не звуковысотной структурой, а спецификой развертывания напева - текстом, построением фраз, ритмикой, наконец, содержанием и назначением музыки.

\section{Нотный пример № 5 . Свадебный напев «Въюн на воде», записан М. Медведевой [12]}
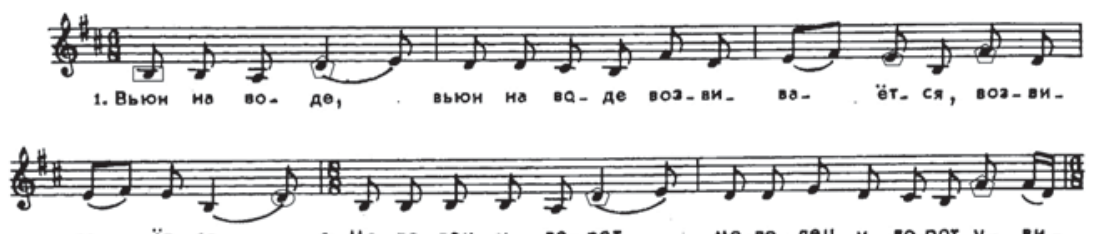

-80_ ёт_ Cя. 2. Мо.ло-дец у во-рот, модло. дец у во-рот у
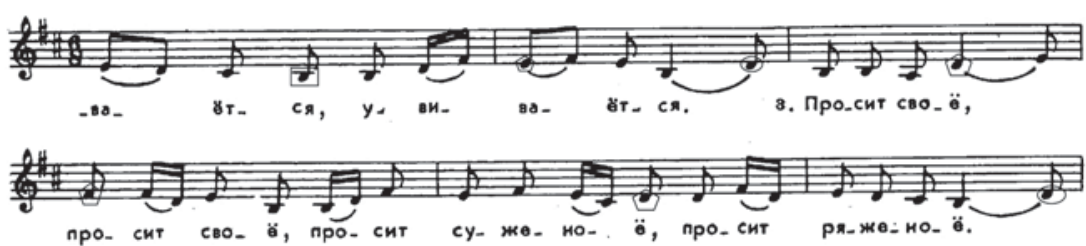

В варианте известного напева, записанном в Костромской области (нотный пример № 5), ступени лада «конкурируют» между собой в опорности. Преимущество начального тона си малой октавы (выделен прямоугольником) как отправной точки и первого устоя оспаривается побочными опорами - тонами фа и ми (выделены пятиугольником), чему способствует их частое повторение, возвращение к ним мелодического развития. Кроме того, эти тоны регулярно озвучивают метрически сильные доли музыкального времени. Но в то же время как итоговый и, следовательно, окончательный устой воспринимается тон ре, завер- шающий напев (выделен овалом). Заметим, что тон ре, главная оппозиция в устойчивости тону си, здесь выступает в двух качествах временной опоры и финалиса, это две разные ладовые функции, в связи с чем мы обозначаем его разными знаками, как будто это две разные ступени лада.

Приведенный образец свадебного напева демонстрирует, что каждая ступень модального лада может выполнять функциональную роль любой другой ступени, «становится на её место», таким образом, в каждой ступени модального лада свернуты все ладовые функции.

Проделанное исследование позволяет выделить ряд признаков модального ладового мышления. Модальные лады пластичны, это их главное свойство. Система звуковысотных отношений здесь не задана изначально, одни и те же звуки лада могут обнаруживать разное качество разные функциональные роли, что исключено в тональности. Для модальной гармонии, напротив, типично то, что каждая ступень лада может, в зависимости от контекста её появления в мелодической линии, выполнять ту или иную функцию. Таким образом, сколько звуков в модальном ладу, столько и возможных гармонических измерений, типов отношений устойчивости-неустойчивости.

Модальная ладовая организация имеет черты политоникальности, и при соответствующих условиях каждый звук может выполнять тонические функции, т.е. играть роль опорного звука, к которому тяготеют остальные. Так, любой звук григорианского хорала, долго выдерживаемый, совпадающий с акцентируемым слогом текста, появляющийся в метрически опорной зоне, воспринимается как представитель местной тоники [13].

Рассмотренные особенности строения и развертывания модальных ладов позволяют сделать ряд обобщений относительно логики музыкальной модальности в ее гармоническом измерении. В отличие от ладов тональной музыки модальные лады:

- не унифицированы, то есть имеют любое количество ступеней и множество их звуковысотных вариантов, которое ограничено лишь представлениями о музыкальном строе; 
- д для них не характерно установленное соответствие между их ступенями и всем множеством звуков музыкального континуума;

- ступени этих ладов могут менять свою высоту и ладовую функцию в процессе развертывания напева;

- каждая ступень модального лада потенциально содержит в себе все ладовые функции;

- одну и туже функцию, в том числе и основной опоры, могут реализовывать несколько ступеней (переменная, блуждающая, рассредоточенная тоника);

- как следствие, в модальном мышлении невозможно транспонирование, то есть точное перенесение напева или мелодии на другую музыкальную высоту или изложение по ступеням другого лада без потери ее узнаваемости.

Для модальных ладов характерны нестабильность звукоряда, структура которого меняется в процессе развития мелодии. Непрерывная модификация препятствует выстраиванию ладового звукоряда в одну линию, имеют место рассредоточенная тоникальность, скользящая тоника, блуждающая тоника - множество устоев, которые многократно перемещаются внутри напева. Такая рассредоточенность порождает динамику, в основе которой лежит движение «ладового мотива» [14] - сочетания основных тонов подряд и на расстоянии. Эта «неконцентрированная» ладовая сущность сродни лингвистической модальности, пронизывающей каждое высказывание даже при отсутствии специальных модальных средств в грамматике. В результате этих факторов модальный лад как гармоническая структура смыкается с мелодией, совпадает с ней, что имеет место в православной системе осьмогласия Мелодия же в свою очередь смыкается с такой глобальной категорией музыки, как жанр, что показывает пример индийской раги; идийская рага или традиционный азербайджанский мугам - это остинатное интонирование тонов лада в определенном порядке. Это проявление модального мышления в музыке можно описать как совпадение структуры и ее наполнения, формы и содержания, как тождество «материи» предмета с самим предметом. С.Л. Франк указывал на это свойство модальности, когда говорил, что Божество никогда не может быть дано как чистая идея, а всегда непосредственно открывается как полновесная конкретная реальность [15].

Мы выделили ряд особенностей, характеризующих логику модального мышления как отличную от логики аналитического музыкального мышления; гармонический и ритмический планы реализации двух этих типов музыкального мышления являются объектом как музыковедческих, так и философских исследований [16]. Модальное мышление в гармонии, противостоящее тональному, является проявлением не только специфического типа художественности, оно так же свидетельствует о существовании особой картины мира, для описания которой следует обращаться уже к построению модальных онтологий.

Модальность является изначальным, исторически первичным типом музыкального мышления. Тем не менее, для подавляющего большинства современных людей, включая жителей азиатских стран, тональное мышление является наиболее «понятными» и «естественными». Об этом свидетельствует стиль популярной эстрадной музыки - во всем мире это музыка исключительно тональная, демонстрирующая более или менее сложные модификации тональных гармонических структур. Музыка же модальная, как старинная, так и современная считается сложной, серьезной, «непонятной», предназначенной для небольшого круга ценителей (в модальных структурах и ладах написаны, к примеру, большинство произведений В. Лютославского, А. Шенберга, К. Дебюсси, О. Мессиана, Р. Щедрина и других композиторов XX-XXI вв.). В контексте нашего исследования такое восприятие объясняется тем, что модальное гармоническое мышление не предполагает стандартных функциональных связей и тяготений, и, следовательно, оно не создает «проторенных» слуховых ходов и гармонических шаблонов. Слушатель такой музыки должен каждый раз заново создавать собственную систему координат, искать гармонические, то есть логические ориентиры.

\section{Библиография:}

1. Zarlino, G. Le Istitutioni harmoniche, p. 4, 1558. - New Haven; London, 1983. - XXIII. - P. 11.

2. Ibid. Диапасон в терминологии 16 века обозначает звукоряд в пределах октавы или сам этот акустически совершенный интервал. 
3. Медушевский, В. В. Интонационная форма музыки. - Москва: Композитор, 1993; Назайкинский, Е. В. Логика музыкальной композиции. - Москва: Музыка, 1982.

4. Бабкина, М. П. Индийская музыка // Энциклопедия Belcanto.ru. - Эл. pecypc. - URL: http://www.belcanto. ru/india.html.

5. Бычков, Ю.Н. Одноголосные диктанты. Приложение // Ю.Н. Бычков. Пособие по курсу сольфеджио для учащихся музыкальных училищ и вузов. - Москва: Российская академия музыки им. Гнесиных, 1996. URL: http://yuri317.narod.ru/d1/pril.htm.

6. Ланглебен, М.М. О некоторых музыкальных системах и музыкальных нотациях древности // Ранние формы искусства. - Москва: Искусство, 1972. - С. 438.

7. Герцман, Е. Античное музыкальное мышление. - Ленинград: Музыка, 1986. - С.5.

8. Бершадская, Т.С. Недоразумение, становящееся традицией (К проблеме: лады тональные - лады модальные) // Музыкальная академия. - 2008. - № 1.

9. Москва, Ю. Основные категории модальности григорианского хорала // Музыкальная академия. - 2007. - № 2. - С. 163.

10. Лебедев, С. О модальной гармонии XIV века // История гармонических стилей: зарубежная музыка доклассического периода. - Вып. 92. - Москва, 1987. - С. 7.

11. Ланглебен, М.М. О некоторых музыкальных системах и музыкальных нотациях древности // Ранние формы искусства. - Москва: Искусство, 1972. - С. 438.

12. Репертуар народного певца / Сост. Л.В. Шамина. - Вып.1. - Москва: Музыка, 1987. - С.8.

13. Этингер, М. Модальная гармония Палестрины и Лассо // История гармонических стилей: зарубежная музыка доклассического периода. - Вып. 92. - Москва, 1987. - С. 64.

14. Юсфин, А. Некоторые вопросы изучения мелодических ладов народной музыки // Проблемы лада. - Москва: Музыка, 1972. - С. 145.

15. Франк, С.Л. Сочинения. - Москва: Правда, 1990. - С. 458.

16. Мёдова, А.А. Аналитическое мышление как отношения во времени: на примере этюда О. Мессиана «Лад длительностей и интенсивностей» // Культура и искусство. - 2013. - № 5. - URL: http://nbpublish.com/ library_read_article.php?id=-26266; Елена Алкон. Мелос, модальность и музыкальное мышление мифологического типа: к развитию идеи Э. Курта // Ученые записки Российской академии музыки имени Гнесиных. - 2014. - №1. -URL: http://www.nbpublish.com/go_to_article.php?id=32371; Мёдова, А.А. О значении понятия modus в логической, лингвистической и музыкальной культуре // Философия и культура. -2015. - №2. - C. 220-229. - URL: http://www.nbpublish.com/go_to_article.php?id=32909

\section{References (transliterated):}

1. Zarlino, G. Le Istitutioni harmoniche, p. 4, 1558. - New Haven; London, 1983. - XXIII. - R. 11.

2. Ibid. Diapason v terminologii 16 veka oboznachaet zvukoryad v predelakh oktavy ili sam etot akusticheski sovershennyi interval.

3. Medushevskii, V. V. Intonatsionnaya forma muzyki. - Moskva: Kompozitor, 1993; Nazaikinskii, E. V. Logika muzykal'noi kompozitsii. - Moskva: Muzyka, 1982.

4. Babkina, M. P. Indiiskaya muzyka // Entsiklopediya Belcanto.ru. - El. resurs. - URL: http://www.belcanto.ru/ india.html.

5. Bychkov, Yu.N. Odnogolosnye diktanty. Prilozhenie // Yu.N. Bychkov. Posobie po kursu sol'fedzhio dlya uchashchikhsya muzykal'nykh uchilishch i vuzov. - Moskva: Rossiiskaya akademiya muzyki im. Gnesinykh, 1996. - URL: http://yuri317.narod.ru/d1/pril.htm.

6. Langleben, M.M. O nekotorykh muzykal'nykh sistemakh i muzykal'nykh notatsiyakh drevnosti // Rannie formy iskusstva. - Moskva: Iskusstvo, 1972. - S. 438.

7. Gertsman, E. Antichnoe muzykal'noe myshlenie. - Leningrad: Muzyka, 1986. - S.5.

8. Bershadskaya, T.S. Nedorazumenie, stanovyashcheesya traditsiei (K probleme: lady tonal'nye - lady modal'nye) // Muzykal'naya akademiya. - 2008. - № 1 .

9. Moskva, Yu. Osnovnye kategorii modal'nosti grigorianskogo khorala // Muzykal'naya akademiya. - 2007. - № 2. - S. 163.

10. Lebedev, S. O modal'noi garmonii XIV veka // Istoriya garmonicheskikh stilei: zarubezhnaya muzyka doklassicheskogo perioda. - Vyp. 92. - Moskva, 1987. - S. 7.

11. Langleben, M.M. O nekotorykh muzykal'nykh sistemakh i muzykal'nykh notatsiyakh drevnosti // Rannie formy iskusstva. - Moskva: Iskusstvo, 1972. - S. 438. 


\section{Культура и искусство 5(29) • 2015}

12. Repertuar narodnogo pevtsa / Sost. L.V. Shamina. - Vyp.1. - Moskva: Muzyka, 1987. - S.8.

13. Etinger, M. Modal'naya garmoniya Palestriny i Lasso // Istoriya garmonicheskikh stilei: zarubezhnaya muzyka doklassicheskogo perioda. - Vyp. 92. - Moskva, 1987. - S. 64.

14. Yusfin, A. Nekotorye voprosy izucheniya melodicheskikh ladov narodnoi muzyki // Problemy lada. - Moskva: Muzyka, 1972. - S. 145.

15. Frank, S.L. Sochineniya. - Moskva: Pravda, 1990. - S. 458.

16. Medova, A.A. Analiticheskoe myshlenie kak otnosheniya vo vremeni: na primere etyuda O. Messiana «Lad dlitel'nostei i intensivnostei» // Kul'tura i iskusstvo. - 2013. - № 5. - URL: http://nbpublish.com/library_read_ article.php?id=-26266; Elena Alkon. Melos, modal'nost' i muzykal'noe myshlenie mifologicheskogo tipa: k razvitiyu idei E. Kurta // Uchenye zapiski Rossiiskoi akademii muzyki imeni Gnesinykh. - 2014. - №1. URL: http://www.nbpublish.com/go_to_article.php?id=32371; Medova, A.A. O znachenii ponyatiya modus V logicheskoi, lingvisticheskoi i muzykal'noi kul’ture // Filosofiya i kul’tura. - 2015. - №2 . - C. 220-229. - URL: http://www.nbpublish.com/go_to_article.php?id=32909 